green is moved along the red-green line the red distribution curve alone is changed.

It is perhaps of interest to note further that if in the last equation $v_{2} \rightarrow \infty$, then $\bar{r} \rightarrow \frac{\bar{x}+\bar{y}}{2}$.

I wish to thank Mr. E. W. H. Selwyn and Dr. W. D. Wright for helpful comments.

Research Laboratories, Kodak, Ltd.

\section{A. Marriage}

Wealdstone, Harrow, Middlesex.

May 12.

\section{Combination Tones}

From time to time attention has been given to the objective reality of so-called 'combination tones' produced when two simple tones are sounded together. We have recently had an opportunity of investigating this experimentally, using a wave analyser of the degenerative type, employing an electronic circuit described by one of $u^{1}$. The analyser has a high selectivity corrresponding to a $Q$ value of about 100 .

An approximately sinusoidal voltage at a frequency of $1,025 \mathrm{c} . / \mathrm{s}$. was superimposed on another approximately sinusoidal voltage of frequency $735 \mathrm{c} . / \mathrm{s}$. , the r.m.s. amplitudes being $200 \mathrm{mV}$. in each case. Search was made for the difference frequency $(290 \mathrm{c.} / \mathrm{s}$.$) and$ the summation frequency $(1,760 \mathrm{c} . / \mathrm{s}$.), and these were found to be practically non-existent. The strength of the $290 \mathrm{c} . / \mathrm{s}$. component was about $1 \mathrm{mV}$., and the summation frequency was too weak to be measured, although its presence was detected.

The analyser was designed to handle a total of $500 \mathrm{mV}$. (with the particular attenuator setting used in the experiment) with minimum distortion. Nevertheless, some slight distortion is to be expected which would give a rectifying effect and would probably account for the traces of combination tones which were observed.

The two input signals were simply added linearly, and quite different results would be expected if the amplitude of one tone were modulated at the frequency of the other.

Pametrada Research Station,

H. G. YATES

R. Catherali

Wallsend-on-Tyne.

Engineer, June 7, 1946.

\section{Sublimation in Outdoor Air}

IN a previous communication ${ }^{1}$, experiments were described on the sublimation of water vapour in a Wilson chamber. It was found that in clean air sublimation commences only at temperatures below $-41 \cdot 2^{\circ} \pm 0.05^{\circ} \mathrm{C}$., whereas in outdoor air at Oxford this threshold temperature is $9^{\circ} \mathrm{C}$. higher.

With the view of investigating conditions at cloudlevel, the Air Ministry arranged for me to visit the Hochalpine Forschungsstation at Jungfraujoch, which is $11,680 \mathrm{ft}$. above sea-level.

During tests lasting three weeks (April 1947) the threshold temperature there was found to be $-4 \mathrm{I} \cdot 2^{\circ} \pm 0.05^{\circ} \mathrm{C}$, with the exception of two days, on which it rose to $-38^{\circ} \mathrm{C}$. The air at Jungfraujoch during these two days was exceptionally hazy. On April 13 (the first occasion) there was an anticyclonic inversion which had developed during the previous night. On the second occasion, April 27, there was an exceptionally strong wind with general instability of the air mass.

It thus appears that whatever sublimation nuclei are effective in the lower air are usually absent from air at the height of Jungfraujoch.

This work is published by permission of the Director of the Meteorological Office.

Clarendon Laboratory, Oxford. June 4.

' Nature, 155, 361 (1945).

\section{Silicon Flame Bands}

WE have recently made a preliminary study of the visible spectrum of flames of hydrogen charged with silicon tetrachloride burning in air. In a Méker burner with restricted supply of air, grey-blue cones are developed, and spectrograms of these taken on a low-dispersion prism instrument show a number of bands, apparently degraded to the violet, in the range $4200-5700 \mathrm{~A}$. The strongest head is at about $5240 \mathrm{~A}$., and a tentative vibrational analysis gives $\omega^{\prime \prime} \sim 750, \omega^{\prime} \sim 1050$ and $\nu_{e} \sim 19,000 \mathrm{~cm}^{-1}$.

The circumstances in which these bands are produced suggest that the emitter may be $\mathrm{Si}_{2}$, and the provisional values of the constants given above do not conflict with this view; but unambiguous identification must await the results of a detailed study with instruments of higher dispersion. This work is in progress.

Sir Leoline Jenkins' Laboratories,

A. R. DOWnte

R. F. Barrow

Jesus College, Oxford.

May 20.

\section{What is a Dialysate ?}

ThE "Oxford Dictionary" defines 'dialysate' as that portion of a mixture that remains after dialysis, and quotes Attfield's "Text-book of Chemistry" (1885). The quotation shows that the part that fails to pass through the membrane is referred to. From the point of view of the lexicographer, this is perfectly satisfactory; there seems to have been no earlier use of the word in print. Graham, for example, although he coined the word 'dialyser' and gave a new meaning to the word 'dialysis' did not apparently use 'dialysate'

Present-day usage does not agree with the "Oxford Dictionary" Nearly all the biochemists that I have consulted have understood by dialysate the more diffusible part of the system. At present, therefore, the word is ambiguous unless the context makes the meaning clear. Many authors and editors have not read Attfield, and some of those who have may question his authority in the matter. The popular meaning has probably been adopted because of the analogy with filtrate, distillate, sublimate, etc.; in each case the more mobile part of the system is referred to. The continuing existence of this analogy will make it difficult to get universal acceptance of the dictionary meaning of dialysate.

We are left with no word except colloid for the part of a system that is retained by the dialysis membrane. This is unfortunate, but it is better than ambiguity.

Rothamsted Experimental Station,

N. W. Pirie

Harpenden. June 12. 